\title{
Intervensi Gizi dalam Penanganan dan Pencegahan Stunting di Asia: Tinjauan Sistematis
}

\author{
Rina Tri Handayani ${ }^{*}$, Aquartuti Tri Darmayanti², Catur Setyorini ${ }^{3}$, \\ Aris Widiyanto ${ }^{4}$, Joko Tri Atmojo ${ }^{5}$ \\ 1,4,5 Program Studi Diploma III Keperawatan, Sekolah Tinggi Ilmu Kesehatan Mamba'ul Ulum, Surakarta \\ ${ }^{2}$ Magister Ilmu Kesehatan Masyarakat, Universitas Sebelas Maret \\ ${ }^{3}$ Program Studi Diploma III Kebidanan, Sekolah Tinggi Ilmu Kesehatan Mamba'ul Ulum, Surakarta \\ *E-mail: trihandayanirina@gmail.com
}

\begin{abstract}
Background: Stunting has dire consequences for children's health in the short term which can decrease cognitive, motor and verbal abilities, increase morbidity and even mortality. Nutrition intervention is absolutely necessary in efforts to reduce and prevent stunting. Purpose this study is to identify nutrition interventions in handling and preventing stunting in Asia. Methods: This search was conducted from September to October 2019, through various databases including PubMed, EMBASE, and CINAHL. Article inclusion criteria: randomized controlled trial, retrospective, observational study, case study, review, systematc review, and meta-analysis. Results: The review results show that in Asia there were 8 specific nutrition programs and 9 sensitive nutrition programs. Conclusion: Interventions for sensitive and specific nutrition programs have been shown to reduce the incidence of stunting and address the long-term effects of stunting in various countries in Asia, but the programming and implementation can be arranged according to country needs and conditions.
\end{abstract}

Keywords: asia, nutrition intervention, stunting

\section{PENDAHULUAN}

Secara global, stunting menurun sekitar $1,8 \%$ per tahun atau hanya akan berkurang $18 \%$ dalam 10 tahun ke depan, hasil ini masih jauh dari target yang diharapkan oleh Majelis Kesehatan Dunia (M. et al., 2013; Hossain et al., 2017). Pada tahun 2017, 55\% balita stunting di dunia berasal dari Asia dan $39 \%$ berasal dari Afrika. Dari 83,6 juta balita stunting di Asia, 58,7\% berasal dari Asia Selatan dan $0,9 \%$ berasal dari Asia Tengah (0,9\%) (Kementrian Kesehatan Indonesia, 2018). Berdasarkan data World Health Organization (WHO), pada regional Asia Tenggara atau South-East Asia Regional (SEAR), Indonesia memiliki prevalensi stunting sebesar 36,4\% sejak 2005-2017, menempatkan Indonesia pada posisi ketiga. Berdasarkan data Pemantauan Status Gizi (PSG) selama tiga tahun terakhir, stunting memiliki prevalensi lebih tinggi dibandingkan gizi kurang, kurus, dan gemuk. Prevalensi stunting mengalami peningkatan dari tahun 2016 yaitu $27,5 \%$ menjadi $29,6 \%$ pada tahun 2017 (Kementerian Kesehatan Republik Indonesia 2018; Widiyanto, et al, 2019).

Stunting memiliki konsekuensi yang mengerikan bagi kesehatan anak-anak. Pada jangka pendek dapat menurunkan kemampuan kognitif, motorik, dan verbal, peningkatan morbiditas bahkan mortalitas akibat infeksi, meningkatnya risiko kematian perinatal dan neonatal, meningkatkan risiko penyakit kronis pada masa dewasa, dan perkembangan anak yang buruk (Stewart et al., 2013; Wali, Agho and Renzaho, 2019). Langkah yang strategis dalam penanggulangan stunting perlu dilakukan, salah satu yang telah dilakukan oleh pemerintah Indonesia terkait menurunkan faktor risiko diatas adalah intervensi gizi berupa langkah 
intervensi gizi sensitif dan intervensi gizi spesifik (Joint Child Malnutrition Eltimates, 2018).

Pemerintah Indonesia telah melakukan intervensi gizi spesifik yang ditujukan untuk menangani penyebab langsung stunting berupa asupan nutrisi dan adanya infeksi, serta intervensi gizi sensitif yang bertujuan untuk mengatasi penyebab tidak langsung seperti ketahanan pangan, akses pelayanan kesehatan, kesehatan lingkungan, serta pengasuhan orang tua (Kementerian Kesehatan Republik Indonesia 2018 ; Widiyanto et al, 2019). Sistematis review ini akan mengidentifikasi studi yang mengidentifikasi program dan komponen intervensi gizi yang telah terbukti berhasil menurunkan prevalensi stunting di berbagai negara di Asia. Penelitian ini bertujuan untuk mengidentifikasi intervensi gizi dalam penanganan dan pencegahan stunting di Asia. Hasil penelitian ini dapat membantu pembuat kebijakan di Indonesia untuk mencegah dan mengontrol stunting.

\section{METODE PENELITIAN}

Penulis melakukan penelusuran database diantaranya PubMed, EMBASE, dan CINAHL untuk mengetahui potensi studi yang memenuhi syarat. Kata kunci yang digunakan antara lain: "stunting in lower and middle income countries" 'ATAU' "stunting and global programme" ATAU "stunting and Indonesia" ATAU "stunting and Asia Region". Penelusuran ini dilakukan mulai dari September hingga Oktober 2019.

Tinjauan ini mempertimbangkan semua studi yang melibatkan komponen PICO diantaranya populasi: anak di bawah 5 tahun (balita 0-59 bulan), Intervensi: intervensi gizi (spesifik, sensitif, atau lainnya), comparison: program kesehatan masyarakat lain untuk mengurangi stunting, outcome: peningkatan tinggi badan. Kriteria artikel yang masuk dalam review kali ini adalah: uji acak terkendali (randomized controlled trial), studi retrospektif, observasional, studi kasus, review, systematc review, dan meta analisis.

\section{HASIL PENELITIAN}

Sejumlah 175 artikel diidentifikasi selama pencarian awal dari seluruh database. Setelah menghilangkan duplikasi dan menerapkan kriteria seleksi, dipilih sebanyak 5 artikel akan dibahas secara kualitatif dalam review ini.

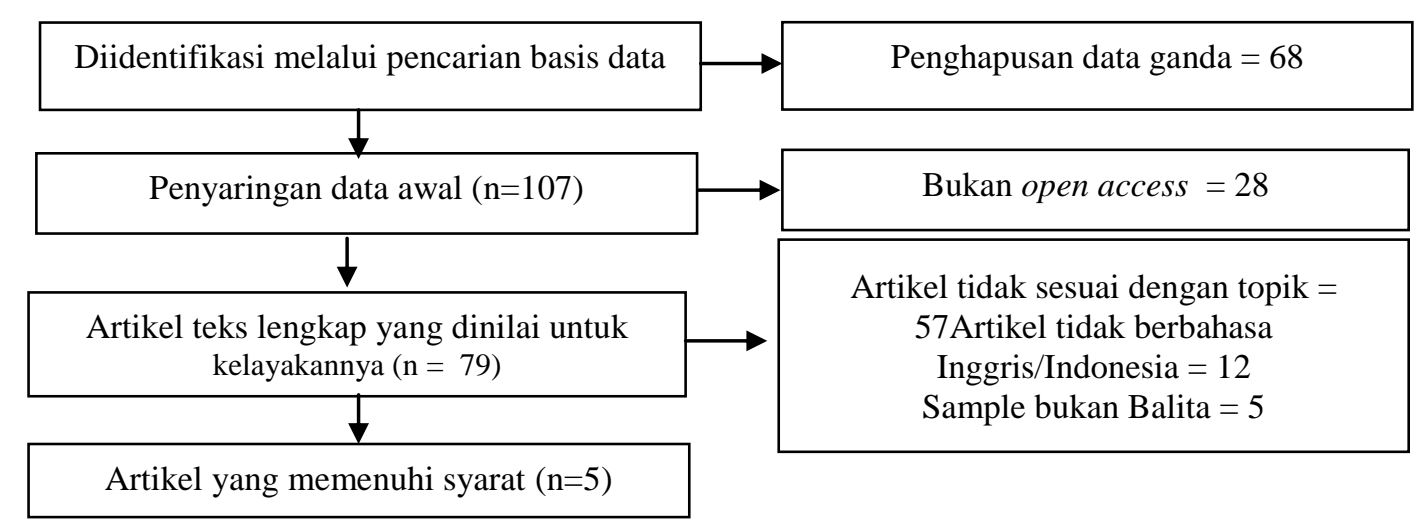

Gambar 1. Alur penelitian 
Hasil pencarian literature didapatkan beberapa program dan intervensi gizi di Asia. Berdasarkan Ruel and Alderman, (2013), dan Hossain et al, (2017) terdapat 8 program intervensi gizi spesifik antara lain yaitu: pertama kesehatan dan nutrisi selama masa remaja, pre konsepsi, masa kehamilan dan menyusui. Kedua yaitu memberikan makanan ibu atau suplemen gizi mikro. Ketiga yaitu mempromosikan pemberian ASI yang optimal. Program keempat yaitu pemberian makanan tambahan, praktik pemberian makan yang responsif dan simulasi pemberian makanan. Program kelima berupa suplementasi makanan, diversifikasi makanan dan suplementasi mikronutrien atau fortifikasi untuk anak-anak. Program keenam berupa pengobatan pada kasus malnutrisi akut parah. Program ketujuh berupa pencegahan dan manajemen bencana, serta kedelapan nutrisi dalam keadaan darurat.

Sedangkan program gizi sensitif yang telah diterapkan antara lain: pertanian dan ketahanan pangan, jaringan keamanan sosial, perkembangan anak usia dini, kesehatan mental ibu, pemberdayaan perempuan, perlindungan anak, sekolah, air, sanitasi dan hygiene, kesehatan dan pelayanan keluarga berencana (Hossain et $a l .$, 2017). Program intervensi gizi ini telah diterapkan di Bangladesh dan Vietnam dan terbukti menurunkan average annual rate of reduction (AARR) atau rata-rata penurunan tahunan untuk stunting hingga 4,5\%. Programprogram yang dilakukan untuk mencegah dan mengobati malaria hanya diterapkan di negara-negara Afrika contohnya Malawi, Niger dan Afrika sub-Sahara di mana terdapat tingkat prevalensi Malaria yang tinggi.
Program dan intervensi gizi di Indonesia spesifik untuk menangani penyebab langsung masalah gizi, berupa pemberian asupan makanan dan timbulnya infeksi pada balita, sedangkan intervensi gizi sensitif lebih luas mencakup masalah tidak langsung terkait gizi dan kebijakankebijakan di sektor pendukung lain seperti pertanian, pendidikan, kebersihan air dan sanitasi, perlindungan sosial, dan pemberdayaan perempuan (Kementerian Kesehatan Republik Indonesia 2018; Widiyanto, et al, 2019). Program gizi yang diterapkan antara lain: intervensi gizi mikro untuk menanggulangi kelaparan dan peningkatan pendidikan. Program selanjutnya yaitu penanggulangan malaria, meningkatkan cakupan imunisasi pada bayi, balita, dan anak. Program kuratif yang dilakukan yaitu pemberian obat cacing pada anak sekolah, pengobatan Tuberkulosis secara tuntas. Program penelitian dan pengembangan yang ditujukan untuk meningkatkan produksi pangan ditujukan untuk mengurangi kelaparan, mempertahankan keanekaragaman hayati, dan mengurangi efek perubahan iklim.

Selain upaya penanggulangan dan program pengobatan, maka investasi pada sistem peringatan dini dari bencana alam juga digunakan dalam pencegahan stunting. Upaya lain berupa peningkatan kapasitas dalam bidang pembedahan, imunisasi hepatitis $\mathrm{B}$, penggunaan obat generik, kampanye mengurangi garam untuk menurunkan kejadian penyakit kronis. Penelitian dan pengembangan geoengineering untuk manajemen radiasi yang lebih baik. Program lain yang ditemukan yaitu bantuan tunai bersyarat dengan penilaian kehadiran sekolah, penelitian dan pengembangan akselerasi 
vaksin HIV. Memperluas uji coba lapangan terhadap kampanye manfaat pendidikan dan intervensi sumur gali dan pompa tangan (Joint Child Malnutrition Eltimates, 2018). Program intervensi stunting di Indonesia, dilaporkan dapat mengurangi kematian anak balita hingga $15 \%$ dan menurunkan prevalensi stunting sekitar 20,3\%, serta mengurangi prevalensi sangat kurus sebesar $61,4 \%$ (Kementrian Kesehatan Republik Indonesia, 2018).

\section{PEMBAHASAN}

Dalam tinjauan sistematis ini intervensi yang dirancang untuk mengurangi stunting di negara-negara Asia membutuhkan kombinasi faktor dan komponen yang bersama-sama memberikan konteks yang sesuai. Komitmen politik yang kuat dan kolaborasi multi-sektoral antara pemerintah, non-pemerintah, nasional dan organisasi internasional menjadi salah satu kunci kesuksesan program (Qirbi and Ismail, 2017). Meskipun intervensi gizi sangat diperlukan, namun bila fokus program hanya pada aspek gizi saja maka cenderung tidak cukup.

Negara seperti Bangladesh, membutuhkan program pendidikan dan konseling, suplementasi vitamin, imunisasi, dan ketahanan pangan. Namun demikian, kombinasi intervensi yang sama tidak sama efektifnya di India. Perbedaan dapat diakibatkan oleh perbedaan kebutuhan, geografis lokasi, organisasi, administrasi, penyelenggaraan intervensi, serta populasi yang menjadi sasaran memiliki efek pada efektivitas intervensi secara keseluruhan. Namun, terdapat beberapa kondisi di mana faktor resiko penyakit menyumbang sebagian besar kemungkinan stunting. Misalnya, di
Indonesia pencegahan dan pengobatan malaria telah menunjukkan manfaat yang signifikan dalam mengurangi stunting di daerah dengan beban malaria yang tinggi (Amouzou, Habi and Bensaïd, 2012; Joint Child Malnutrition Eltimates, 2018).

Pada tahun 2012, WHO menargetkan pada tahun 2025 penurunan stunting pada anak dibawah 5 tahun sebesar $40 \%$. Secara global sekitar 3,9\% setiap tahunnya dan menyiratkan pengurangan angka kejadian stunting hingga 71 juta pada 2010 menjadi sekitar 100 juta pada 2025. Namun dengan laju kemajuan saat ini, diperkirakan 127 juta anak akan mengalami stunting pada tahun 2025. Maka agar target stunting global tercapai, negara diharapkan untuk menentukan bagaimana mereka akan berkontribusi dan menetapkan target mereka sendiri. Menerjemahkan global target menjadi target nasional yang bergantung pada profil gizi, tren faktor risiko, perubahan demografis, implementasi kebijakan gizi dan peningkatan sistem kesehatan (de Onis and Branca, 2016).

\section{KESIMPULAN DAN SARAN}

Intervensi program gizi sensitif dan spesifik telah terbukti mampu menurunkan kejadian stunting dan menangani efek jangka panjang dari stunting di berbagai negara di Asia dan Indonesia. Meskipun program yang dijalankan tidak sama persis, karena penyusunan dan pelaksanaan program dapat disusun berdasarkan kebutuhan dan kondisi negara. Program intervensi gizi hendaknya disesuaikan dengan budaya masing-masing tempat target.

\section{DAFTAR RUJUKAN}

Amouzou, A., Habi, O. and Bensaïd, K. 
(2012). Reduction in child mortality in Niger: A Countdown to 2015 country case study. The Lancet. doi: 10.1016/S0140-6736(12)61376-2.

Hossain, M. et al. (2017). Evidence-based approaches to childhood stunting in low and middle income countries: A systematic review. Archives of Disease in Childhood, 102(10), pp. 903-909. doi: 10.1136/archdischild2016-311050.

Joint Child Malnutrition Eltimates. (2018). Buletin Stunting. Journal of Molecular Biology, 301(5), pp. 1163-1178.

M., D. O. et al. (2013). The world health organization's global target for reducing childhood stunting by 2025: Rationale and proposed actions. Maternal and Child Nutrition.

De Onis, M. and Branca, F. (2016). Childhood stunting: A global perspective. Maternal and Child Nutrition, 12, pp. 12-26. doi: 10.1111/mcn.12231.

Qirbi, N. and Ismail, S. A. (2017). Health system functionality in a lowincome country in the midst of conflict: The case of Yemen. Health Policy and Planning. doi: 10.1093/heapol/czx031.

Ruel, M. T. and Alderman, H. (2013) 'Nutrition-sensitive interventions and programmes: How can they help to accelerate progress in improving maternal and child nutrition?', The Lancet. doi: 10.1016/S0140-

\section{6(13)60843-0.}

Stewart, C. P. et al. (2013). Contextualising complementary feeding in a broader framework for stunting prevention. Maternal and Child Nutrition. doi: 10.1111/mcn.12088.

Wali, N., Agho, K. and Renzaho, A. M. N. (2019). Past drivers of and priorities for child undernutrition in South Asia: a mixed methods systematic review protocol. Systematic Reviews. Systematic Reviews, 8(1), pp. 1-8. doi: 10.1186/s 13643-019-1112-7.

Widiyanto, A., Atmojo JT., Darmayanti AT. (2019). Pengaruh faktor kerawanan pangan dan lingkungan terhadap stunting. Jurnal Terpadu Ilmu Kesehatan. Vol 8. Pp. 61-66. 